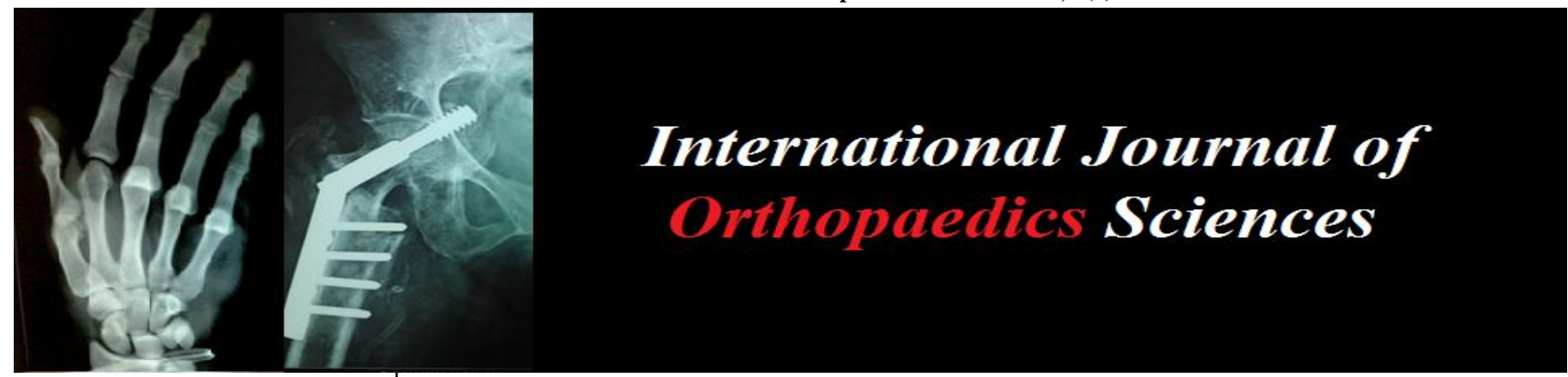

ISSN: 2395-1958

IJOS 2017; 3(1): 792-796

(C) 2017 IJOS

www.orthopaper.com

Received: 23-11-2016

Accepted: 24-12-2016

Dr. N Venkatesh Kumar

Associate Professor,

Department of Orthopaedics

PSGIMSR, Coimbatore, India

Dr. Arvind Kumar SM

Professor,

Department of Orthopaedics

PSGIMSR, Coimbatore, India

Dr. Udayamoorthy S

Junior Resident,

Department of Orthopaedics

PSGIMSR, Coimbatore, India

Dr. Sanjeev S

Junior Resident,

Department of Orthopaedics

PSGIMSR, Coimbatore, India

Correspondence

Dr. N Venkatesh Kumar

Associate Professor,

Department of Orthopaedics

PSGIMSR, Coimbatore, India

\section{Functional outcome of Tibial condyle fractures treated by minimally invasive plate osteosynthesis}

\author{
Dr. N Venkatesh Kumar, Dr. Arvind Kumar SM, Dr. Udayamoorthy S \\ and Dr. Sanjeev $S$
}

DOI: http://dx.doi.org/10.22271/ortho.2017.v3.i11.113

\section{Abstract}

Introduction: Tibial plateau fractures with intra-articular extension are very difficult to manage. Age, skin conditions, compartment syndrome and osteoporosis further increase the obstacles in the healing process.

Complex biomechanics of its weight bearing position and complex ligamentous stability and articular congruency are the main reason why these fractures are of concern to surgeon.

In our study we have evaluated the functional outcome of locking plate fixation of tibial condyle fractures using minimally invasive technique, a minimum period of 6 months after plate fixation by Rasmussen score and Knee society score.

Materials and Methods: Tibial plateau fractures treated by minimally invasive plate osteosynthesis using locking compression plate from January 2010 to January 2015 were taken into the study. All the patients who had completed the inclusion criteria were called for assessment of functional outcome of knee using Rasmussen score and knee society score.

Results and Discussion: In our study, we were able to get away with unilateral plating for type V and type VI fractures without any late complications like loss of reduction and malalignment.

Choice of the procedure/implant should be based on the fracture pattern, bone quality and intraoperative reduction.

Conclusion: Treatment of intraarticular tibial plateau fractures is still unsolved.

Our results in minimally invasive percutaneous plate osteosynthesis (MIPPO) technique is in par with the literature.

Keywords: Tibial fracture, Schatzker, osteosynthesis, implants

\section{Introduction}

The knee joint is complex and most commonly injured joint now because of increased motor vehicle accidents and sports related injuries. As it is a superficial joint, it is more exposed to external forces and gets easily injured. Tibial plateau fractures with intra-articular extension are very difficult to manage. Age, skin conditions, compartment syndrome and osteoporosis further increase the obstacles in the healing process.

Complex biomechanics of its weight bearing position and complex ligamentous stability and articular congruency are the main reason why these fractures are of concern to surgeon. The ideal treatment of high-energy tibial plateau fractures is controversial. Open reduction and stable internal fixation helps in maintaining the articular surface and restoration of the mechanical alignment which allows early mobilization of knee. But, techniques of open reduction and internal fixation compromise the soft tissues and the rate of wound infection is relatively high.

Various other methods of treatment like hybrid fixation and now plate fixation using minimally invasive technique have been suggested. Each method has its own advantage and disadvantages. The development of locking implants has allowed the use of minimally invasive technique for unilateral plating ${ }^{[37-39]}$ with improvement in handling the soft tissue ${ }^{[40-43]}$.

There are lot of studies which assess the general outcome of these fractures but there are only few studies which assess the functional outcome of these fractures which is more important to the patient. In our study we have evaluated the functional outcome of locking plate fixation of tibial condyle fractures using minimally invasive technique, a minimum period of 6 months after plate fixation by Rasmussen score and Knee society score. 


\section{Materials and methods}

Tibial plateau fractures treated by minimally invasive plate osteosynthesis using locking compression plate from January 2010 to January 2015 were taken into the study.

\section{Inclusion criteria}

Age group: 18 years to 60 years all tibial condyle fracture treated by minimally invasive plate osteosynthesis.

\section{Exclusion criteria}

1) Skeletally immature patients,

2) Neurovascular injuries,

3) Concomitant lowerlimb fractures like patella, femur, ankle and pelvic fractures.

4) Open fractures

\section{Methodology}

This was both retrospective as well as a prospective study. For the retrospective study in-patients and out-patient records of the study population were collected from the medical records department and OT register. Age, gender of the patients, mode of injury, side of involvement, Associated injuries and medical comorbidities were documented. The Neurovascular status of the affected leg, compartment syndrome and any blisters or open wounds was noted. All Tibial condyles fractures were graded preoperatively using Schatzker classification. Patients were followed up postoperatively after a minimum period of six months after surgery. All the patients who had completed the inclusion criteria were called for assessment of functional outcome of knee using Rasmussen score and knee society score.

\section{Results}

$\mathrm{n}$ our study, 13 patients belonged to type VI, 6 patients belonged to type V, 2 patients belonged to type IV, 1 patient belonged to type III and type II respectively.

\section{Total Number of Patients}

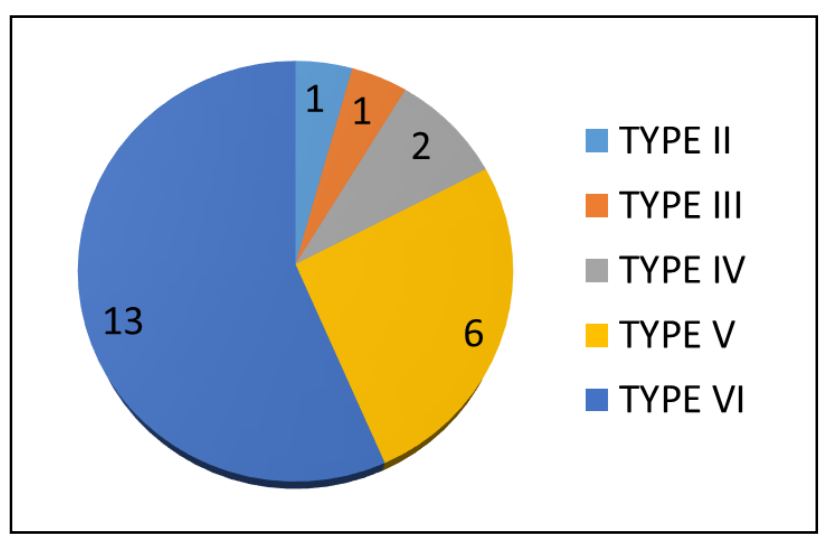

Thirteen patients had right tibial plateau fractures and remaining ten patients had left tibial plateau fractures. Only fractures which were treated with MIPPO technique were taken for the study. RTA was the mode of injury in all the cases. In our study type VI Schatzker fractures was the commonest type. Functional assessment was assessed by Rasmussen score (subjective score) and knee society score (objective score). Average follow up period was 22.08 months.

\section{Mean Follow Up}

\begin{tabular}{|l|c|c|}
\hline SL.NO & TYPE & $\begin{array}{l}\text { AVERAGE } \\
\text { (MONTHS) }\end{array}$ \\
\hline 1. & I & - \\
\hline 2. & II & $17(6-17)$ \\
\hline 3 & III & $18(6-18)$ \\
\hline 4. & IV & $32.5(6-47)$ \\
\hline 5. & V & $19.8(6-27)$ \\
\hline 6. & VI & $23.1(6-53)$ \\
\hline
\end{tabular}

In type VI Schatzker there were thirteen patients of whom seven patients were treated by lateral plating and six patients were treated by medial plating. Mean Rasmussen score of type VI fractures was found to be 25.6, average knee society score was found to be 93.2 and mean range of knee flexion was found to be 118.8 degrees. All the patients were started on partial weight bearing from 8 weeks and full weight bearing by 12 weeks.

\section{Average Scores by Knee Society and Rasmussen Score}

\begin{tabular}{|c|c|c|c|}
\hline $\begin{array}{c}\text { Sl. } \\
\text { No }\end{array}$ & Type & Knee Society Score & Rasmussen Score \\
\hline 1 & 1 & - & - \\
\hline 2 & 2 & 98 & 27 \\
\hline 3 & 3 & 96 & 29 \\
\hline 4 & 4 & 94 & 26.4 \\
\hline 5 & 5 & 81.3 & 22.8 \\
\hline 6 & 6 & 93.2 & 25.6 \\
\hline
\end{tabular}

Six patients belonged to type V Schatzker group. Mean follow up was 19.8 months (6-27). Lateral plating was done for 2 patients and medial plating was done for 4 patients. Average Rasmussen score was 22.8 , mean knee society score was 81.3 and average range of knee flexion was found to be 118.3 degrees. Only one patient had flexion contracture of 10 degrees. All the patients were started on partial weight bearing at 8 weeks and full weight bearing was started at $12^{\text {th }}$ week. Postoperatively there were no wound infections.

In type IV Schatzker fractures there were two patients. Mean follow up was found to be 32.5 months (6-47). All patients were treated by medial plating. Average range of flexion was found to be 122.5 degrees. Mean Rasmussen score was found to be 26.5. Mean knee society score was found to be 94 . There was no wound infection and weight bearing was started at $12^{\text {th }}$ week. In our study only one patient belonged to type III Schatzker fracture. Follow up was done at 18 months (6-18). He was treated by lateral plating and had Rasmussen score of 29. Range of flexion was found to be 120 degrees. Knee society score was found to be 96 . No complications were noted.

In type II Schatzker there was only one case which met the criteria. Lateral plating was done. Follow up was done at 17 months (6-17). Rasmussen score was found to be 27 , knee society score was 98 and range of knee motion was 125 degrees. No complications were noted. No bone grafts used in our study. 


\section{Discussion}

Intraarticular tibial plateau fractures are complex fractures accounting for about $1.2 \%$ of all fractures. They affect knee function and stability which results in considerable morbidity. These fractures are caused by high velocity injuries and often associated with severe comminution and soft-tissue damage. The goals of treatment are to restore joint congruity, limb alignment and early mobilisation of joint. Stable internal plate fixation without damaging the soft-tissue envelope is very difficult to achieve, only fair results are seen in $20 \%$ to $50 \%$ in these fractures. Outcome after tibial plateau fracture fixation depends mainly on knee range of motion and strength of the quadriceps. Knee stiffness is more clinically relevant than instability in these fractures.

Open reduction and internal fixation (ORIF) with plates and screws enables direct fracture visualisation, reduction, and fixation, but there is high risk of soft tissue injury, stiffness and deep infection. The hybrid external fixator avoids soft tissue problems, but risks non-union, pin tract infections and poor patient compliance.

The concept of preserving the blood supply and atraumatic surgical technique led to the development of biological fixation techniques. Using this technique, soft tissue damage is reduced and shows higher union rate.

The development of locking implants has allowed the use of minimally invasive technique for unilateral plating ${ }^{[37-39]}$ with improvement in handling the soft tissue ${ }^{[41-43]}$.

Laterally placed locking plates provide better stability in the presence of complex proximal $1 / 3^{\text {rd }}$ tibia fracture with metaphyseal comminution and serves as an alternative to medial plate or external fixator for additional support of the medial column when a non-locking plate is used for bicondylar fractures. This plate allows fixation through single incision which avoids wound dehiscence, infection and prolonged immobilisation associated with extensile approaches.

MIPPO enables indirect fracture reduction and percutaneous sub muscular implant placement. Favourable outcome is not due to MIPPO but due to less extensive dissection of softtissue envelope and devitalisation of fracture fragments.

The aim of our study was to evaluate the functional outcome of tibial condyle fractures treated by minimally invasive percutaneous plate osteosynthesis. There is no universal scoring system for assessing the functional outcome for these fractures. Literature shows multiple scoring system like Rasmussen, knee society score and oxford knee score. In our study, we have evaluated the patients using Rasmussen score which is subjective score and knee society score which is an objective score. All these fractures were treated by a single plate either medial or lateral (11 lateral and 12 medial). In case of type V and type VI fractures, if needed the opposite condyle was fixed with percutaneous cancellous screws.

Mechanism of injury was road traffic accident for all these patients. The fractures were classified by Schatzker's classification. 13 patients belonged to type VI, 6 patients belonged to type V, 2 patients belonged to type IV, 1 patient belonged to type III and type II respectively. Even though, according to literature type II fractures were the most common, only one patient with type II fracture was included in our study as all other type II \& type I fractures in the study period were fixed only by percutaneous screws hence excluded from the study. Type VI fracture with 13 patients $(56.5 \%)$ were the most common in our study, next was type V (26.08) with 6 patients. Average followup period was 22 months (653). Hasnain Raza et al, in their study of assessing the functional outcome of tibial condyle fractures of 41 patients by minimally invasive plate osteosynthesis by Rasmussen functional score found excellent results in 18 patients, good in 19 patients and 4 patients had unacceptable results. The mean Rasmussen score was found to be 25.3 and range of knee flexion was 118 degrees. In our study mean Rasmussen score was found to be 26.1 and average range of knee flexion was found to be 120.9 degrees. Of which ten patients had excellent and good results each. Only 3 patients had fair results. This is comparable to the study done by Hasnain Raza. Mohammad Ali Tahririan, Seyyed Hamid Mousavitadi, and Mohsen Derakhshan ${ }^{[13]}$ in their clinical study comparing the functional outcomes of tibial plateau fractures treated with nonlocking and locking plate fixation by knee society score, found a score of 80.2 for locking plate and 72.5 for non-locking plate. Average range of knee flexion was found to be 122.3 degrees for locking plate and 115.7 degrees for non-locking plate. In our study, locking plate was used for all the cases. Average knee society score was found to be 92.5 and average knee flexion was found to be 120.9 degrees. So, functional outcome in our study was marginally better than the locking plate group in that study and significantly better than the non-locking group. This shows the superiority of the locking plate in view of stable fixation and early range of motion when compared to non-locking plate. Chang-Wug Oh et al ${ }^{[18]}$ in their study on double plating of (twenty three) type V and type VI proximal tibial fractures using minimally invasive percutaneous osteosynthesis found Eighteen patients with excellent, three patients with good and two patients with fair results. Average Rasmussen score was found to be 26 and average knee range of motion was found to be 123 degrees. In our study, nineteen patients belonged to type V and VI fractures. Average Rasmussen score of these type $\mathrm{V}$ and type VI fractures were found to be 24.2. Average range of flexion achieved by type $\mathrm{V}$ and type VI was found to be 118.5 degrees. Seven patients had excellent, ten patients with good and two patients had poor results. In their study of ten patients Kye-Youl Cho et al ${ }^{[5]}$, used a single midline longitudinal incision and dual plating for the treatment of type V and type VI schatzker fractures. Their mean knee society score for the study group was 85 and the mean range of motion was 125 degrees. They had only one case with delayed wound healing as postoperative complication. In our study, average knee society score was found to be 87.25 . One patient had 10 degrees of valgus malalignment in type VI fracture and one patient had flexion contracture of 5-10 degrees. But the functional outcome was not significantly altered when compared with others.

Dual plate gives better biomechanical strength and rigid construct thereby better control of both columns thus avoiding late collapse. There were no major wound problems in any of these studies. Weight bearing was started only at 8-12 weeks which was similar to our study. In our study, we were able to get away with unilateral plating for type $\mathrm{V}$ and type VI fractures without any late complications like loss of reduction and malalignment.

Choice of the procedure/implant should be based on the fracture pattern, bone quality and intraoperative reduction. 
CASE 1:

Preop Xray

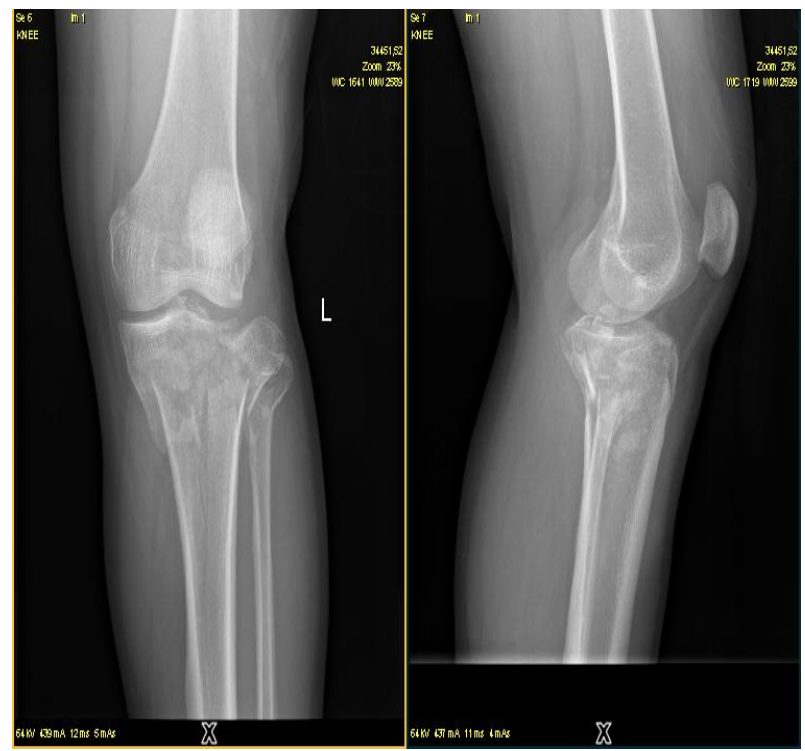

\section{Immediate Postop Xray}

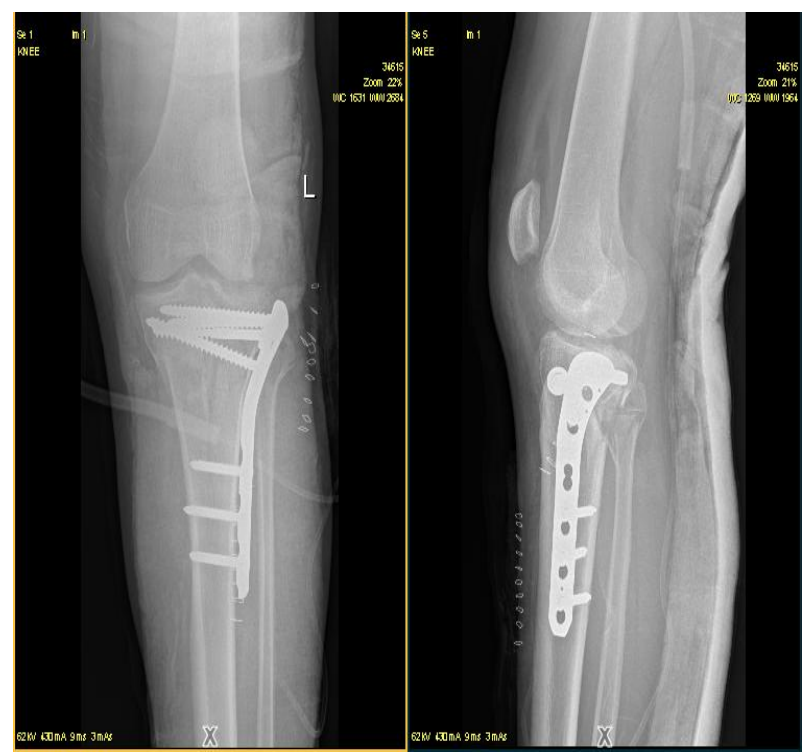

After 6 Months

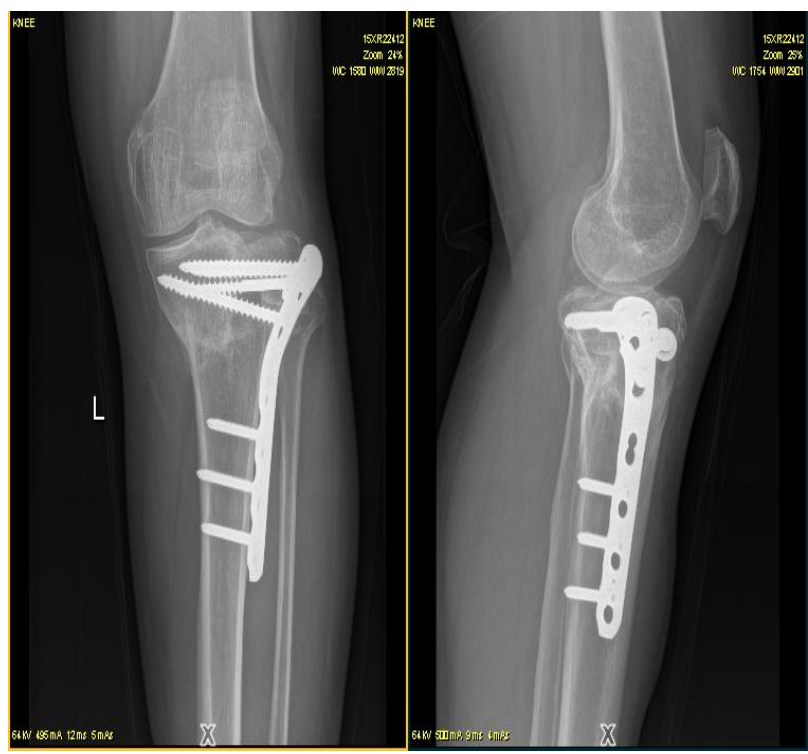

Clinical Picture

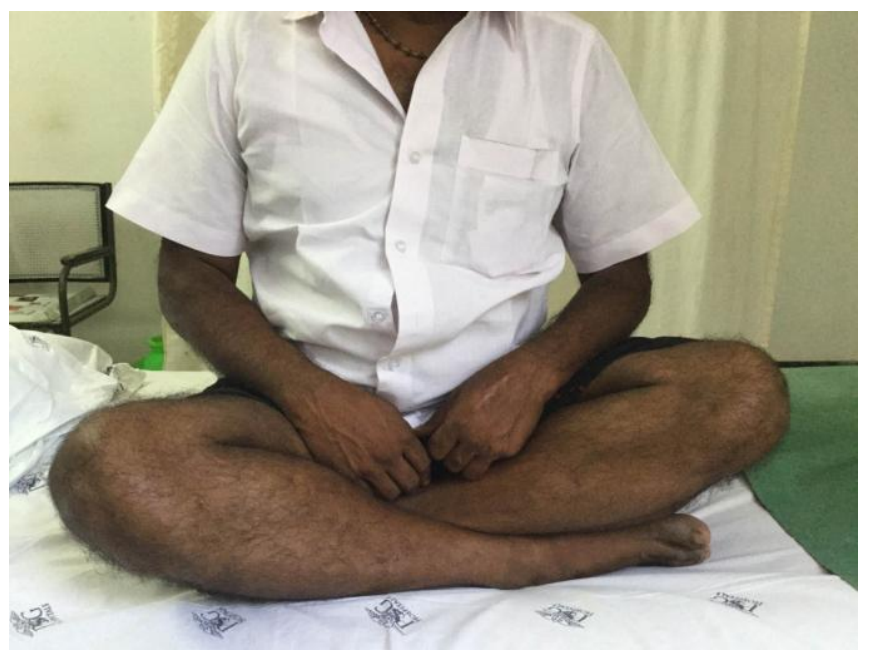

\section{Conclusion}

Treatment of intraarticular tibial plateau fractures is still unsolved. Our results in minimally invasive percutaneous plate osteosynthesis (MIPPO) technique is in par with the literature. There is no significant difference in the functional outcome between single plating in our study and dual plating of other studies at midterm followup. Choice of the procedure/implant should be based on the fracture pattern, bone quality and intraoperative fracture reduction.

\section{Reference}

1. Douglas $\mathrm{R}$ Dirschl, Daniel Del Gaizo. Staged Management of Tibial Plateau Fractures A Supplement to The American Journal of Orthopedics. 2007.

2. Comparison of outcome of unilateral locking plate and dual plating in the treatment of bicondylar tibial plateau fractures Lee et al. Journal of Orthopaedic Surgery and Research. 2014; 9:62.

3. Tibial plateau fractures treated with the less invasive stabilisation system. Jackson A. Lee \& Stamatios A. Papadakis \& Charles Moon \& Charalampos G. Zalavras International Orthopaedics (SICOT) 2007; 31:415-418.

4. New trends and techniques in open reduction and internal fixation of fractures of the tibial plateau. Musah V, Tarkin I, Kobbe P, Tzioupis C, Siska PA, Pape HC. 2009 British Editorial Society of Bone and Joint Surgery 2009. 91-B, 4.

5. Treatment of Schatzker Type V and VI Tibial Plateau Fractures Using a Midline Longitudinal Incision and Dual Plating. Kye-Youl Cho, Hyun-Sup Oh, Jae-Ho Yoo, DukHyun Kim, Young-Joo Cho, Kang-Il Kim. Knee Surg Relat Res, 2013; 25(2).

6. Traditional buttress plating v/s MIPO in management of proximal tibial fractures - A clinical study. Rakesh Sharma, Rajesh Kapila, Brahm Preet Singh, Yadwinder Singh Sohal. Pb Journal of Orthopaedics. 2013, 1.

7. Results of proximal tibial fractures managed with periarticular locking plates: A series of 34 cases. Jain D, Selhi HS, Mahindra P, Kohli S, Yamin M. IJRRMS 2012; 2(4).

8. Apley AG. fractures of the lateral tibia condyle treated by skeletal traction and early mobilization. A review of sixty cases with special reference to the long term result, J Bone Joint Surg 1956; 38-B:699,

9. Schatzker J, McBroom R, Bruce D. The tibial plateau fracture. The Toronto experience 1968-1975. Clin Orthop Relat Res. 1979; 138:94-104. 
10. Diass JJ, Stirling AJ, Finlay DBL, Gregg PJ. Computerised axial tomography for tibial plateau fractures, J Bone Joint Surg 1987; 69-B:84.

11. Barei DP, Nork SE, Mils WJ. Functional outcome of severe bicondylar tibial plateau fractures treated with dual incision and medial and lateral plates. J Bone Joint Surg. 2006; 88-A:1713-1721.

12. Tscherne H, Lobenhoffer P. Tibial plateau fractures. Management and expected results. Clin Orthop Relat Res. 1993; 292:87-100.

13. Clinical Study Comparison of Functional Outcomes of Tibial Plateau Fractures Treated with Nonlocking and Locking Plate Fixations: A Nonrandomized Clinical Trial. ISRN Orthopedics Volume March Article ID324573 Mohammad Ali Tahririan, Seyyed Hamid Mousavitadi, Mohsen Derakhshan. 2014,

14. Functional and radiological evaluations of high energy tibial plateau fractures treated with double buttress plate fixation. Yu Z, Zheng L, Zhang Y, Li J, Ma B. Eur J Med Res. 2009; 14:200-205.

15. Recovery of knee function following fracture of the tibial plateau. Gaston P, Will EM, Keating JF. J Bone Joint Surg [Br] 2005; 87-B:1233-6.

16. Albuquerque RP, Hara R, Prado J, Schiavo L, Giordano V, Amaral NP. Epidemiological study on tibial plateau fractures at a level I trauma center. Acta Ortop Bras. [online]. 2013; 21(2):109-15.

17. Comparison of Outcomes of Operatively Treated Bicondylar Tibial Plateau Fractures by External Fixation and Internal Fixation. Malaysian orthopaedic Journal CC Chan, MRCS (Ed), J Keating, FRCS Orth (Ed). 2012; 6(1).

18. Double plating of unstable proximal tibial fractures using minimally invasive percutaneous osteosynthesis technique. Chang-Wug, Jong-Keon, Hee-Soo Kyung. InHo Jeon, Byung-Chul Park, Woo-Kie Min et al. Acta Orthopaedica. 2006; 77(3):524-530.

19. David Levay. History of Orthopaedics 1990, 625:592,

20. Sir Robert Jones. Orthopaedic surgery of injuries 1921; $1: 86$,

21. Wilson Wg, Jacobs JE. Patellar graft for severely depressed comminuted fractures of the lateral tibial condyle. J Bone Joint Surg 1952; 34A:436,

22. Rasmussen PS. Tibial condylar fractures. Impairment of knee joint stabilityas an indication for surgical treatment. J Bone Joint Surg Am. 1973; 55:1331-50.

23. Moore TM, Harvey JP, JR.: Roentogenographic measurement of tibial plateau depression due to fractures: J Bone Joint Surg 1974; 56A:155,

24. Drennen DB, Loucher FG, Maylahn DJ. Fractures of the tibial plateau treatment by closed reduction and spica cast, J Bone Joint Surg. 1979; 61-A:989,

25. Bowes DN, Hohl M. Tibial condyle fractures: evaluation of treatment and outcome, Clin Orthop 1982; 171:104.

26. Blokker $\mathrm{CP}$, Rorabeck $\mathrm{CH}$, Bourne RB. Tibial plateau fractures. An analysis of the results of treatment in 60 patients. Clin Orthop. 1984; 182:193,

27. Insall JN, Dorr LD, Scott RD, Scott WN. Rationale of the knee society clinical rating system. Clin Orthop Relat Res. 1989; (248):13-4.

28. Delamarter R, Hohl M. The cast brace and tibial plateau fractures, Clin Orthop 1987; 242:26.

29. Jensen DB, Rude C, Duus B, Bjerg-Nielsen A. Tibial plateau fractures. A comparison of conservative and surgical treatment. J Bone Joint Surg; 1990; 72B:49-52,
30. Honkonen SE, Jarvienen MJ. Classification of fractures of tibial condyles, J Bone Joint Surg 1992; 74B:840,

31. Marsh JL, Smith ST, Do TT. External fixation and limited internal fixation for complex fractures of the tibial plateau. J Bone Joint Surg 1995; 77A:661,

32. Cambell s operative orthopaedics; Fractures of lower extremity: Tibial plateau 3, 2094-2111

33. Weigel DP, Marsh JL. High energy fracture of the tibial plateau: knee function after longer follow-up. J Bone Joint Surg 2002; 84-A:1541-1551,

34. Ali AM, Bruton M, Hashmi M, Saleh M. outcome of complex fractures of the tibial plateau treated with a beam loading ring fixation system. J Bone Joint Surg. 2003; 85B:691-699,

35. Lubowitz JH, Elson WS, Guttmann D. Arthroscopic management of tibial plateau fracture part-I: Arthroscopy. 2004; 20:1063-1070.

36. Duwelius PJ, Connolly JF. Closed reduction of tibial plateau fractures a comparison of functional and roentogenographic and results, Clin Orthop. 1988; 230:116.

37. Farouk O, Krettek C, Miclau T. Minimally invasive plate osteosynthesis: does percutaneous plating disrupt femoral blood supply less than the traditional tech- nique? J Orthop Trauma. 1999; 13:401-6.

38. Farouk O, Krettek C, Miclau T, Schandelmaier P, Tscherne H. Effects of percu- taneous and conventional plating techniques on the blood supply to the femur. Arch Orthop Trauma Surg. 1998; 117:438-41. 